\title{
MENINGKATKAN KETRAMPILAN MENYUSUN PTK MELALUI PEMBIMBINGAN GURU KELAS VIII SMP BINAAN DI DINAS PENDIDIKAN DAN KEBUDAYAAN KABUPATEN SRAGEN SEMESTER I TAHUN PELAJARAN 2017/2018
}

\author{
Subakdi \\ Pengawas Sekolah SMP Dinas Pendidikan dan Kebudayaan Kabupaten Sragen, Jawa Tengah \\ bakdisubakdi59@gmail.com
}

\begin{abstract}
Classroom action research is evidence to the performance of professional teachers. The action taken by due to the problems that were in the class and is done by organized. This study aimed to improve the skill of PTK structure through teacher guidance. The subjects of the study were six teachers in the target school, two teachers of class VIII in SMP N 2 Sidoharjo, two teachers of class VIII in SMP N 2 Kedawung, one teachers of class VIII in SMP N 1 Jenar, and one teachers of class VIII in SMP N 1 Gondang. The research period was completed on July 18, 2017 up to December 31, 2017. The research was conducted with 2 coaching guidance. Each cycle consists of 4 stages, namely planning, implementation, observation or evaluation, and reflection. The results of the School Action Study conducted by Ssupervisors were teacher's skill to arrange PTK after being guided from 53\% to 80\%, there were also reports of 6 documents of PTK or $100 \%$, and the act of mentoring looked maximal with score 93\%. Based on the results of research can be concluded VIII grade junior high school teacher skills in target area of Sragen regency in the first semester of academic year 2017/2018 for preparing PTK can be improved through coaching.
\end{abstract}

Keywords: skill to arrange PTK, guidance, cclassroom action research

\begin{abstract}
Abstrak. Penelitian Tindakan Kelas merupakan bukti kinerja guru profesional. Tindakan yang dilakukan itu merupakan akibat adanya masalah-masalah yang dihadapi di kelas dan dilakukan dengan teroganisir. Tujuan penelitian adalah untuk meningkatkan ketrampilan menyusun PTK melalui pembimbingan guru. Subyek penelitian adalah enam guru di sekolah binaan yaitu dua guru kelas VIII di SMP N 2 Sidoharjo, dua guru kelas VIII di SMP N 2 Kedawung, satu guru kelas VIII di SMP $\mathrm{N} 1$ Jenar, dan satu guru kelas VIII di SMP N 1 Gondang. Waktu penelitian dilakukan tanggal 18 Juli 2017 sampai dengan tanggal 31 Desember 2017. Penelitian dilakukan melalui tindakan pembimbingan sebanyak 2 siklus. Tiap siklus terdiri dari 4 tahap, yaitu perencanaan, pelaksanaan, pengamatan atau evaluasi, dan refleksi. Hasil Penelitian Tindakan Sekolah yang dilakukan Pengawas adalah terdapat kenaikan ketrampilan guru menyusun PTK setelah dibimbing dari 53\% menjadi $80 \%$, terdapatnya hasil laporan PTK 6 eksemplar atau 100\%, dan tindakan pembimbingan tampak maksimal dengan skor 93\%. Berdasarkan hasil penelitian dapat disimpulkan bahwa ketrampilan guru SMP kelas VIII di SMP binaan kabupaten Sragen Semester I tahun pelajaran 2017/2018 dalam menyusun PTK dapat ditingkatkan melalui pembimbingan.
\end{abstract}

Kata Kunci: ketrampilan menyusun PTK, pembimbingan, penelitian tindakan kelas 


\section{Pendahuluan}

Penelitian Tindakan Kelas (PTK) adalah penelitian yang dilaksanakan oleh guru di kelasnya untuk membuat lebih mengerti terhadap pekerjaannya, memperbaiki, praktik-praktik kerja, dan melakukan inovasi pembelajaran yang selalu berkembang mengikuti zaman. Ciri utama PTK adalah melakukan tindakan nyata untuk memperbaiki situasi dalam upaya meningkatkan mutu pembelajaran sehingga mampu menghasilkan siswa yang berpikir kritis, kreatif, inovatif, cakap dalam meyelesaikan masalah, dan bernaluri kewirausahaan (Ditjen PMPTK, 2010).

Menyusun dan melaksanakan Penelitian Tindakan Kelas merupakan bukti kinerja guru profesional. Tindakan yang dilakukan itu merupakan akibat adanya masalahmasalah yang dihadapi di kelas dan dilakukan dengan teroganisir dalam perencanaan, pelaksanaan, pengamatan, serta refleksi. Ketika guru mengetahui persoalan, tidak hanya menganalisis saja, tetapi juga perlu berbuat sesuatu tindakan untuk memecahkan persoalan tersebut. Mengubah strategi, pendekatan dan metode pembelajaran bertujuan meningkatkan mutu pembelajaran yang ditandai meningkatnya prestasi belajar peserta didik.

Dengan demikian, pengawas sekolah sebagai seorang peneliti selain menjelaskan masalah terpilih yang didapat, juga terlibat dalam memecahkan masalah-masalah yang ada di lokasi penelitian. Sudah sewajarnya jika pengawas sekolah selalu mendorong guru untuk mengatasi masalah yang ada. Berpedoman terhadap hal yang dirasakan oleh guru, maka manfaat penilaian tindakan kelas bagi guru, antara lain meningkatkan keterampilan dan sikap profesional, menumbuhkembangkan budaya akademik sehingga tercipta sikap proaktif di dalam melakukan perbaikan mutu pembelajaran secara ilmiah, meningkatkan mutu proses pembelajaran, membuat guru menjadi peka dan tanggap terhadap masalah-masalah yang muncul, meningkatkan kinerja guru, dan hasil belajar siswa, guna mendapatkan angka kredit untuk perabot kenaikan pangkat jabatan dan atau serifikasi guru (Dirjen PMPTK, 2009).

Kemampuan guru dalam menyusun PTK ternyata masih mengalami berbagai kendala. Kelemahan guru terutama tentang evaluasi diri sekolah di setiap pelaksanaan Standar Nasional Pendidikan, khususnya standar proses, standar isi, dan standar kompetensi lulusan. Kelemahan guru-guru tersebut dapat diupayakan oleh guru sendiri, dengan bimbingan pengawas sekolah dan dengan perlakuan tindakan di kelas mereka. Menghadapi kondisi semacam ini peneliti ingin melakukan penelitian tindakan sekolah terhadap guru kelas VIII di daerah binaan peneliti sebagai pengawas sekolah, agar guru-guru tersebut dapat melakukan penelitian tindakan dan menuliskan laporannya berupa PTK sebagai bukti fisik kinerja guru profesional. Keberhasilan suatu proses pembelajaran dipengaruhi oleh berbagai komponen yang ada didalamnya, antara lain : tujuan, bahan atau materi, model pembelajaran, media dan pendidik (Zainudin, 2015).

\section{Metode}

Tempat penelitian ini dilaksanakan di Sekolah Binaan SMP Kabupaten Sragen yaitu SMP N 2 Sidoharjo, SMP N 2 Kedawung, SMP N 1 Jenar, dan SMP N 1 Gondang. Subyek penelitian adalah enam guru di sekolah binaan yaitu 2 guru kelas VIII di SMP N 2 Sidoharjo, 2 guru kelas VIII di SMP N 2 Kedawung, 1 guru kelas VIII di SMP N 1 Jenar, dan 1 guru kelas VIII di SMP N 1 Gondang. Waktu penelitian dilakukan tanggal 18 Juli 2017 sampai dengan tanggal 31 Desember 2017.

Tindakanyang dilakukandalampenelitian berupa bimbingan khusus menyusun PTK secara bertahap : siklus I dan siklus II melalui tahap perencanaan, tahap pelaksanaan, tahap pengamatan atau observasi dan tahap refleksi/ berpikir ulang kembali. Teknik pengumpulan data kuantitas keterampilan menyusun PTK dilakukan dengan menghitung jumlah PTK 
yang disusun. Sedangkan data kualitas kelayakan PTK dikumpulkan dengan teknik mengevaluasi atau menilai laporan PTK, menggunakan alat berupa lembar evaluasi.

Teknik analisis data menggunakan analisis kualitatif deksriptif. Setiap butir lembar evaluasi kelayakan PTK diskor melalui 4 kategori yaitu skor 4 jika layak, skor 3 jika cukup layak, skor 2 jika kurang layak, dan skor 1 jika tidak layak. Sedangkan data tindakan pembimbingan dalam lembar pengamatan bimbingan ada 25 butir. Setiap butir mendapat kategori; skor 3 jika indikator keberhasilan tampak maksimal, skor 2 jika indikator tampak kurang maksimal, dan skor 1 jika indikator tidak tampak. Skor bimbingan bergerak antara 25 sampai 75. Perolehan skor 25-41 atau 33\% - 55\% (indikator bimbingan tidak tampak), perolehan skor $42-58$ atau $56 \%$ - 78\% (indikator bimbingan tampak kurang maksimal) dan perolehan skor 59-75 atau 79\%-100\% (indikator bimbingan tampak maksimal).

Penelitian ini dilakukan melalui tindakan pembimbingan sebanyak 2 siklus. Tiap siklus terdiri dari 4 tahap yaitu : perencanaan, pelaksanaan, pengamatan atau evaluasi, dan refleksi.

\section{Hasil}

Tabel 1. Rata-rata Data Awal, Akhir Siklus I dan Akhir Siklus II

\begin{tabular}{llccccc}
\hline No & Data Penelitian & Data Awal & Siklus I & Siklus II & $\begin{array}{c}\text { Total } \\
\text { Kenaikan }\end{array}$ & Keterangan \\
\hline & Keterampilan & & & & & \\
menyusun PTK & & & & & \\
1. & a. Kuantitas PTK & $16,66 \%$ & $71,43 \%$ & $100 \%$ & $83,34 \%$ & Cukup layak \\
& b. Kualitas PTK & $53 \%$ & $67 \%$ & $80 \%$ & $27 \%$ & Cukup layak \\
2. & Pembimbingan & $49 \%$ & $77 \%$ & $93 \%$ & $44 \%$ & Tampak \\
& & & & & & maksimal \\
\hline
\end{tabular}

\section{Pembahasan}

\section{Deskripsi Kondisi Awal}

Sebelum dilaksanakan bimbingan, diketahui bahwa kuantitas keterampilan menyusun PTK dari subjek penelitian adalah $16,66 \%$, karena hanya ada 1 laporan penelitian tindakan dari 6 Guru SMP Kelas VIII yang menjadi subjek penelitian. Sedangkan kualitas laporan penelitian setelah dievaluasi menggunakan lembar evaluasi, hasilnya 53\%, sehingga masih termasuk katagori kurang layak.

\section{Siklus I}

Materi pembimbingan yaitu Modal Penelitian Tindakan Kelas untuk Pelatihan Profesional Guru dalam PTK dari Dirjen PMPTK, 2010. Materi ini dijadikan acuan atau pedoman bagi subjek penelitian dalam menyusun PTK. Pembimbingan dilakukan secara individu karena judul, masalah, dan tingkat pemahamannya berbeda dari 6 guru SMP kelas VIII sebagai subjek penelitian.

Pada awal bimbingan subjek hanya membawa hasil Evaluasi Diri yang dibuat oleh guru sendiri tentang kelemahan-kelemahan dan kelebihan diri di sekolah. Kelemahan rata-rata terdapat pada penggunaan alat peraga dalam proses pembelajaran yang dilakukan guru kelas VIII.

Hasil evaluasi diketahui bahwa dari 6 subjek penelitian sudah menghasilkan 5 PTK atau 71,43\%. Dari 5 PTK tersebut setelah dievaluasi tingkat kelayakannya rata-rata mendapat skor 70 atau tampak masih ada dua PTK yang kurang layak atau kurang memenuhi ketentuan tetapi, telah menunjukkan adanya peningkatan kemauan menulis hasil pekerjaannya. Data pengamatan dari kolaborator, serta pengamatan dari salah satu subjek penelitian, diperoleh data skor tindakan pembimbingan dari kolaborator 
yaitu 57 atau 76\%, sedangkan dari Guru Kelas VIII SMPN 2 Sidoharjo mendapat skor 58 atau $76 \%$ dengan rata-rata 57,5 atau $77 \%$ sehingga pembimbingan yang diperoleh masih memerlukan pendampingan lebih lanjut.

Untuk mengetahui apakah keterampilan menyusun PTK meningkat, maka hasil pengamatan pada akhir siklus I dibandingkan dengan data awal. Diketahui bahwa kuantitas PTK mengalami kenaikan 54,77\% yaitu dari 16,66\% menjadi 71,43\%. Kualitas PTK naik $14 \%$ dari semula $53 \%$ menjadi $67 \%$. Pelaksanaan tindakan pembimbingan naik $27,5 \%$ dari semula $49 \%$ menjadi $77 \%$ namun indikator pembimbingan masih tampak kurang maksimal.

\section{Siklus II}

Materi yang disiapkan peneliti adalah tentang tata tulis, pembahasan, dan pembuatan power point untuk paparan. Pembimbingan dilakukan secara individu dan kelompok dihadiri oleh semua subjek penelitian. Masing-masing subjek membawa PTK, antara lain pada bagian tata tulis dan bagian pembahasan, terdapatnya tata tulis yang belum beraturan. Guru Kelas VIII mulai mengamati dari berbagai paparan peneliti dengan mengganti judul dan hasil penelitian sesuai PTK masing-masing. Subjek penelitian datang untuk pembimbingan terakhir, hasil PTK dikumpulkan untuk dievaluasi menggunakan lembar evaluasi yang telah disediakan sebelumnya.

Hasil pengamatan pembimbingan PTK yang dilaporkan kolaborator telah berjalan dengan baik dan berhasil memacu semangat para subjek penelitian. Tampak sudah ada 6 eksemplar PTK dari subjek menyusun PTK, sehingga data kuantitatif 100\%. Data kualitas kelayakan PTK rata-rata skor 83 atau $80 \%$ sehingga rata-rata dapat disebut cukup layak. Hasil pengamatan tindakan peneliti dalam membimbing subjek penelitian pada siklus II diperoleh dengan menghitung skor hasil pengamatan yang dilakukan oleh kolaborator dan salah satu Guru SMP Kelas VIII. Data skor pengamatan dari kolaborator adalah 66 dan dari Guru SMP Kelas VIII SMP N 2 Sidoharjo yaitu 74, dengan rata-rata skor pembimbingan adalah 70 atau 93\%, sehingga masuk dalam tingkatan indikator pembimbingan sudah kelihatan maksimal sesuai harapan.

Berdasarkan data dalam Siklus II dapat diketahui bahwa sudah $100 \%$ subjek menyusun PTK. Dalam segi kualitas sudah mencapai 80\%, walaupun masih dalam kategori cukup layak, namun sudah memperoleh kenaikan 13\% dibanding siklus I. Pada pelaksanaan tindakan, indikator pembimbingan sudah tampak maksimal yaitu 93\% atau mengalami kenaikan 16\%.

Data kuantitas PTK terdapat peningkatan dari data awal sampai akhir siklus II yaitu, dari data awal $16,66 \%$ menjadi $100 \%$, ada kenaikan sebesar 83,34\%. Data kualitas PTK meningkat dari data awal 53\% menjadi $80 \%$ atau cukup layak pada akhir siklus II, ada kenaikan sebesar 27\%. Data keberhasilan pembimbingan yang dilakukan peneliti, data awal adalah $49 \%$ atau nampak kurang maksimal, walaupun kurang maksimal peneliti tetap berusaha agar hasil yang didapat sesuai dengan yang diharapkan, terbukti sampai siklus II menjadi $93 \%$ atau berarti tampak maksimal, sehingga terjadi kenaikan sebesar $44 \%$.

Perlakuan tindakan peneliti dalam membimbing subjek, yang semula dilakukan dengan indikator pembimbingan, belum tampak karena hanya terlalu banyak ceramah. Oleh sebab itu, peneliti sebagai pengawas sekolah melakukan dengan pendekatan interpersonal atau hubungan antar pribadi yang saling asah asih, asuh, maka hasil indikator pembimbingan dapat tampak maksimal.

Indikator keberhasilan dari tindakan yang dilakukan dapat diraih dengan buktibukti seperti tersebut di bawah ini:

1. Terdapat bukti naiknya keterampilan menyusun PTK setelah dibimbing, dari data awal 53\% menjadi 80\% (data dalam siklus II). 
2. Terdapat hasil laporan PTK sebanyak 6 eksemplar atau $100 \%$ yang semula hanya 1 eksemplar atau $16,66 \%$.

3. Skor kualitas kelayakan laporan PTK 83 atau $80 \%$ kategori cukup layak.

4. Skor pengamatan tindakan pembimbingan 70 atau $93 \%$ kategori tampak maksimal.

\section{Simpulan}

Berdasarkan hasil penelitian dapat disimpulkan bahwa ketrampilan guru SMP kelas VIII di SMP binaan kabupaten Sragen Semester I tahun pelajaran 2017/2018 dalam menyusun PTK dapat ditingkatkan melalui pembimbingan. Tindakan pembimbingan telah memberi hasil dengan dasar terdapatnya data indikator keberhasilan. Keberhasilan itu dibuktikan dengan terjawabnya masalah dan tercapainya tujuan penelitian pada bab I yaitu : naiknya keterampilan menyusun PTK setelah dibimbing, dari data awal 49,98\% menjadi $83,3 \%$ pada akhir siklus II, terdapat hasil 6 eksemplar laporan PTK, semula hanya 1 eksemplar atau $16,66 \%$ menjadi $100 \%$ pada akhir siklus II, kualitas kelayakan laporan PTK kategori cukup layak yaitu dari data awal $53 \%$ menjadi $80 \%$ pada akhir siklus II, tindakan pembimbingan tampak maksimal dari data awal $49,98 \%$ menjadi $83,3 \%$ pada akhir siklus II.

\section{Saran}

Berdasarkan kesimpulan penelitian, peneliti menyampaikan saran sebagai berikut : (1) Pengawas Sekolah jika menjumpai masalah yang sama dapat mengadopsi dan mengadaptasi langkah-langkah yang telah ditempuh oleh peneliti dalam meningkatkan keterampilan Guru SMP Kelas VIII. Namun, harus mempersiapkan diri untuk mendalami materi bimbingan sehingga mampu mengubah dan meningkatkan semangat maju berprestasi para guru, (2) Guru SMP Kelas VIII agar dibiasakan melakukan tindakan tiap satu semester sekali, untuk memperbaiki kelemahan pada penerapan 8 Standar Nasional Pendidikan. Tindakan yang dilakukan para guru diharapkan dapat membuat kenyamanan kerja dan merasa senang, tidak malu, serta dapat melakukan perbaikan pembelajaran akan dapat ditingkatkan secara berkelanjutan sesuai dengan harapan kebutuhan di sekolah.

\section{Daftar Pustaka}

Depdikbud. (1993). Pedoman Bimbingan Guru dalam Kegiatan Belajar Mengajar, Dirjendikdasmen.

Dirjen PMPTK. (2009). Bahan Belajar Mandiri Kelompok, Kerja Kepala Sekolah, Penelitian Tindakan Sekolah, Dirjen PMPTK, Depdiknas.

Dirjen PMPTK. (2010). Penelitian Tindakan Sekolah, Materi Pelatihan Penguatan Keterampilan Kepala Sekolah, Ditendik, Dirjen PMPTK, Kementrian Pendidikan Nasional.

Imron Ali. (2009). Penelitian Tindakan Sekolah untuk Kepala Sekolah dalam rangka Peningkatan Kinerja Pembelajaran, Dirjen PMPTK, Depdiknas.

Permendiknas Nomor 39 tahun 2009 tentang Pemenuhan Beban Kerja Guru dan Pengawas Satuan Pendidikan.

Sukardi. (2003). Metodologi Penelitian Pendidikan, Kompetensi dan Praktiknya, Jakarta : Bumi Aksara.

UU RI Nomor 20 Tahun 2003. Tentang Sistem Pendidikan Nasional.

Zainudin, M., Puspananda, D.R. (2015). Efektivitas Direct Instruction Dengan Involving Students In Self-And Peer Evaluation Terhadap Hasil Belajar Ditinjau Dari Gaya Kognitif. Varia Pendidikan, 27( 2):192-199. 